Brit. J. prev. soc. Med. (1975), 29, 228-238

\title{
Asthma in schoolchildren \\ Demographic associations and peak expiratory flow rates compared in children with bronchitis
}

\author{
RICHARD F. HAMMAN, T. HALIL, AND W. W. HOLLAND \\ Department of Community Medicine, St Thomas's Hospital Medical School, London
}

\begin{abstract}
Hamman, R. F., Halil, T., and Holland, W. W. (1975). British Journal of Preventive and Social Medicine, 29, 228-238. Asthma in schoolchildren. The frequency of asthma in 10971 schoolchildren between the ages of 5 and 14 years was reported by their parents to be $3 \cdot 8 \%$. Of these, $20.7 \%$ were said to have had bronchitis, $5.9 \%$ pneumonia, and $4.7 \%$ eczema. Asthma was reported more commonly in boys than girls and was greatest in children of social classes I and II. One-third of the children were reported to have had their first attack before the age of 2 years. Few (18\%) first attacks started after the age of 5 years. There was no evidence that bronchitis predisposed to the later development of asthma, or vice versa. Within each age-sex group children with a history of asthma had lower peak expiratory flow rates than children who gave no such history. These differences in PEFR were greater than for children with a history of bronchitis.
\end{abstract}

The likelihood that chronic bronchitis has its origins in childhood has been emphasized by several population studies (Lunn, Knowelden, and Handyside, 1967; Douglas and Waller, 1966; Ferris, 1970; Rosenbaum, 1961; Colley, 1971; Reid, 1964). These studies have stressed the importance of episodes of probable lower respiratory tract infections (bronchitis and pneumonia) in childhood causing permanent impairment of lung function. The prevalence of these illnesses, and impaired ventilatory capacity, are affected by personal and environmental factors such as sex, area of residence, social class, and smoking habits (Holland et al., 1969a, b; Holland, Halil, and Elliott, 1969; Bennett et al., 1971).

Asthma, which in common with chronic bronchitis may lead to eventual disablement from airways obstruction, also often begins in childhood (Williams and McNicol, 1969), but the aetiology of this disease is not completely understood. If it shares a common cause with chronic bronchitis this may be apparent in comparable epidemiological behaviour of the two diseases in childhood.

In the present study, data collected in a survey of Kent schoolchildren (Holland et al., 1969) were used to estimate the prevalence of childhood asthma, to explore associations between certain demographic, social, personal, and medical characteristics of children who had a history of asthma and to compare these with similar data from children in the same survey population who had a history of bronchitis or bronchitis and asthma.

\section{METHODS}

The major survey methods used in this study have been described previously (Bennett et al., 1971; Holland et al., 1969, 1969a, b, 1970). Asthma was defined as a positive response by parents when questioned whether their child had ever had asthma and if so, at what age the first $ᄋ$ attack occurred. Similar techniques were used to define the prevalence of bronchitis, pneumonia, eczema, sinus infection, and other illness in these children.

Of all children attending state schools in the $\tilde{O}$ survey area $6 \%$ did not respond. Special schools $\underset{\omega}{N}$ for the physically handicapped were investigated $\square$ and of $\mathbf{4 4}$ children from the survey areas attending 6 these, only five had a history of asthma. There $\mathbb{\Phi}$ were not, therefore, large clusters of asthmatics $\stackrel{?}{?}$ 
unable to attend regular schools in this area of Kent. Children at private schools were not investigated in this study.

Since recall of a history of asthma (or bronchitis) by parents was the variable used to identify and classify cases, attempts were made to validate those responses. From the original sample of 10971 children, 1975 were re-examined approximately 3 years after the initial study in 1967 and 1968. This was a stratified random sample weighted so that it included $50 \%$ of children in the lowest quintile of standardized peak expiratory flow rate (PEFR) and $10 \%$ of the remaining upper four quintiles. Of the 1975 children selected for follow-up, 1570 participated $(79.5 \%)$ with equivalent response rates in each quintile. In this study, all members of the family including the index child were questioned and examined using the same questionnaire that had been used in the initial investigation.

Peak expiratory flow rates were measured taking the average of three consecutive readings for each individual recorded with a Wright Peak Flow Meter.

\section{RESULTS}

Correspondence and Validity of Parental RESPONSES

The reliability of parental reports of illness in their children as measured by the correlation of responses on two different occasions is shown in Table I. At the second questioning 3 years later, parents failed to remember $6.5 \%$ of children (4 of 62) previously noted to have had asthma, $17 \%$ of those with pneumonia, and $23.9 \%$ of those reported with bronchitis.

Since there was a 3-year period between the initial and follow-up examinations, negative to positive changes reported may have included new illness episodes since the initial survey in 196465 . Therefore, reports which changed from negative to positive were analysed taking into consideration the age at first illness. New cases were considered to have occurred when a new illness was reported at the second examination at an age greater than the age at the first examination. There were $0.7 \%$ new cases of asthma over 'the 3-year period', $0.6 \%$ new cases of pneumonia, and $2.6 \%$ new episodes of bronchitis. When the age at first attack as stated at follow-up was less than the actual age of the child at initial examination (for those with initially negative histories), or when an initially positive history was reported as negative at followup, these cases were considered more likely to be genuine reporting discrepancies. There was an overall discrepancy rate of $1.3 \%$ for asthma, $2 \cdot 1 \%$ for pneumonia, and $10 \cdot 8 \%$ for bronchitis.

Discrepancies in reporting may arise for two reasons. The sensitivity and specificity of the questionnaire may be different on the two occasions (this was unlikely in this study because the same questions were used) or there may be differences in the memory of parents. The rates of discrepancy for positive to negative and negative to positive change were examined by age, sex, number of siblings, social class, mother's educational level, and area of residence of the child to elucidate whether discrepancies were dependent on the characteristics of the child or the parent. No significant or meaningful associations were found between discrepancy rates and these characteristics. Although there are recall errors in reporting respiratory illnesses, these cannot explain diffeiences in the association of respiratory illnesses with area of residence, social class, age, sex, or any of the other measured factors, since they operate equally in all such sub-groups.

It was hoped that a review of the records of a sample of general practitioners (GPs) could validate the hypothesis that the parental report was an underestimate of true disease incidence. Some GP records of children in the study were surveyed

TABLE I

CORRESPONDENCE OF PARENTAL REPORTS OF ILLNESS AT INITIAL AND FOLLOW-UP EXAMINATIONS

\begin{tabular}{|c|c|c|c|c|c|c|c|c|}
\hline & & & \multicolumn{6}{|c|}{ First Examination } \\
\hline & & & \multicolumn{2}{|c|}{ Asthma } & \multicolumn{2}{|c|}{ Pneumonia } & \multicolumn{2}{|c|}{ Bronchitis } \\
\hline & & & Positive & Negative & Positive & Negative & Positive & Negative \\
\hline \multicolumn{9}{|c|}{ Second examination } \\
\hline positive & .. & .. & 58 & 27 & 83 & 25 & 271 & 115 \\
\hline negative & . & .. & 4 & 1481 & 17 & 1445 & 85 & 1099 \\
\hline Total $\ldots$ & .. & .. & 62 & 1508 & 100 & 1470 & 356 & 1214 \\
\hline
\end{tabular}


in the summer of 1971 and the three groups shown were selected so that approximately equal numbers of cases occurred in each of the residence areas.

Group 1 Cases reporting at the initial interview that asthma, bronchitis, or pneumonia had occurred but not reporting such an illness on followup, and cases with discrepancies in the reverse direction.

Group II Cases stating both at initial and follow-up interviews that asthma, bronchitis, or pneumonia had occurred.

GrouP III Cases stating at both investigations that no illness had ever occurred.

Table II shows that, of the records studied, $29 \cdot 5 \%, 31 \cdot 5 \%$, and $29 \cdot 2 \%$ were considered incomplete by the auditor for asthma, pneumonia, and bronchitis respectively. Even though the proportion of incomplete records differed significantly between age groups no consistent trends were noted.

TABLE II

PROPORTION (\%) OF GP RECORDS CONTAINING INSUFFICIENT INFORMATION TO VALIDATE PARENTAL REPORTING OF ILLNESS

\begin{tabular}{ll|c|c|c|c}
\hline \multirow{2}{*}{\multicolumn{1}{c|}{ Illness }} & & \multicolumn{2}{c|}{ Age of Child at Initial Examinations } \\
\cline { 3 - 6 } & & $5-8$ & $9-13$ & $14+$ & All Ages \\
\hline \multirow{2}{*}{ Asthma } &. & $32 \cdot 0$ & $18 \cdot 3$ & $41 \cdot 9$ & $29 \cdot 5$ \\
Bronchitis &.. & $31 \cdot 4$ & $20 \cdot 2$ & $38 \cdot 7$ & $29 \cdot 2$ \\
Pneumonia &. & $32 \cdot 6$ & $18 \cdot 3$ & $41 \cdot 9$ & $31 \cdot 5$ \\
& & & & & \\
\hline \multirow{2}{*}{ Population } &.. & 175 & 109 & 62 & 346 \\
\hline
\end{tabular}

It was hoped that those children within the lowest quintile of adjusted PEFR might be reflected by more complete and valid data in the GP record since lung function is reduced significantly by a report of respiratory illness. For all three illnesses a higher proportion of records with information missing was recorded for children in the lowest quintile, a finding opposite to that expected.

In those records considered complete, the agreement between parental report that an illness had occurred at any time in the past and in the GP's record was poor. The agreement was $54.8 \%$ for asthma, $39 \%$ for pneumonia, and $42.4 \%$ for bronchitis. The GP reports were thus found to be an inadequate source to verify the illness reports of the parents.

Because a higher proportion of disease episodes were forgotten than were reported as new over the 3 years, it appears that an underestimate of actual disease prevalence occurred, being least for asthma, intermediate for pneumonia, and largest for bronchitis by using parental recall data.

\section{Age AND SeX}

Our results were obtained from a population of 10971 schoolchildren, 414 of whom were identified as having a history of asthma. The prevalence of reported asthma, bronchitis, pneumonia, ande eczema in six age-sex groups is shown in Table III $3.8 \%$ of the children were said to have had asthma, $20.7 \%$ bronchitis, $5 \cdot 9 \%$ pneumonia, and $4.7 \%$ eczema.

The figures for asthma and pneumonia showed an increase in frequency from the 5-8 year to the 9-13 year age group in both boys and girls. With asthma the 14 years + age group had a slightly lower rate than the 9-13 year age group. The rates for bronchitis, by comparison, decreased with

TABLE III

PREVALENCE (\%) OF REPORTS OF ASTHMA, BRONCHITIS, PNEUMONIA, AND ECZEMA IN KENT SCHOOLCHILDREN

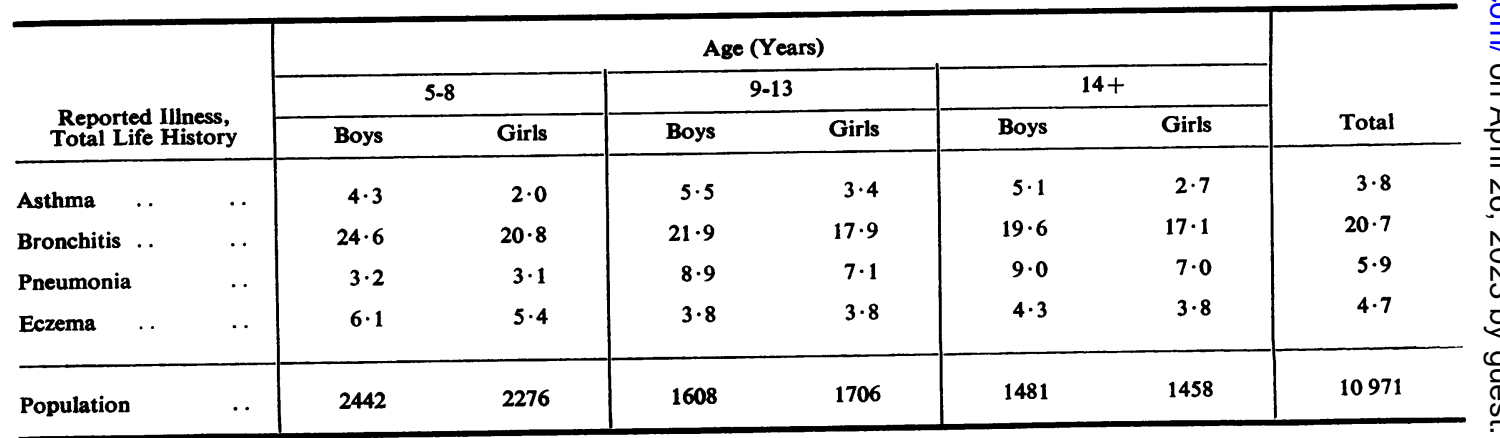


increasing age. Table III also illustrates the difference in sex ratio in the three conditions. There was an almost two-fold excess of boys in each age group with reported asthma, whereas for bronchitis and pneumonia there were only slightly more boys.

\section{InCIDENCE OF ASTHMa AS COMPARED WITH BRON- CHITIS}

One-third of the children were reported to have had their first attack of asthma between birth and 2 years of age. Few first attacks (18\%) occurred after the age of 5 years. A larger proportion of children, about $50 \%$, had their first attack of bronchitis before the age of 2 but, as with asthma, few first attacks $(19 \%)$ occurred after the age of 5 years.

\section{Social Class}

Frequency of reported asthma was greatest in social classes I and II and least in social classes IV and $\mathrm{V}$ as shown in Table IV. This diminishing

TABLE IV

PREVALENCE (\%) OF REPORTS OF CHILDREN WITH ASTHMA BY SEX AND SOCIAL CLASS

\begin{tabular}{|c|c|c|c|c|c|}
\hline \multirow{2}{*}{\multicolumn{2}{|c|}{ Sex }} & & \multicolumn{3}{|c|}{ Social Classt } \\
\hline & & & $\mathbf{I}+\mathbf{I I}$ & III & $\mathbf{I V}+\mathbf{V}$ \\
\hline Boys & .. & . & $6 \cdot 9$ & $4 \cdot 9$ & $3 \cdot 8$ \\
\hline Girls & .. & .. & $3 \cdot 6$ & $2 \cdot 5$ & $1 \cdot 8$ \\
\hline Total & Boys & .. & 1003 & 2873 & 1312 \\
\hline Total & Girls & .. & 982 & 2872 & 1245 \\
\hline \multicolumn{3}{|c|}{$\begin{array}{l}\text { Percent asthma } \\
\text { both sexes }\end{array}$} & $5 \cdot 2^{*}$ & $3 \cdot 7^{*}$ & $2 \cdot 9 *$ \\
\hline
\end{tabular}

$x^{2}=17 \cdot 58, \mathrm{df}=2, \mathrm{P}<0.001$

$\dagger 684$ children social class unknown, $3 \cdot 3 \%$ with asthma

gradient with decreasing social class was seen in both sexes, and more boys than girls were found within each social class grouping. It was in the opposite direction from the gradient reported previously for these children with bronchitis (Bennett et al., 1971; Holland et al., 1969, 1969a, b, 1970).*

Because these differences could perhaps be attributed to the misclassification of asthma or

*We have used the Registrar-General's Classification of Occupations for assigning Social Class. Social Class I are professional and managerial occupations, Social Class III, skilled workers, Social Class V are unskilled workers, Social Class II and IV are intermediate to these. bronchitis we examined the prevalence of asthma in association with bronchitis, asthma on its own, and bronchitis on its own, by social class. As Table V shows, the same relationship of asthma with social class was apparent whether we examined only those children labelled as asthmatic or included children who also had a history of bronchitis. There were similar proportions of children in each illness category whose social class was unknown, and the results were not altered by their exclusion from Table V.

\section{AREA of Residence}

Table VI shows the prevalence of reported asthma by area of residence and social class. Area of

\section{TABLE V}

PREVALENCE (\%) OF REPORTS OF CHILDREN WITH ASTHMA AND BRONCHITIS BY SOCIAL CLASS

\begin{tabular}{|c|c|c|c|}
\hline \multirow[b]{2}{*}{ Illness } & \multicolumn{3}{|c|}{ Social Class* } \\
\hline & $\mathbf{I}+\mathbf{I I}$ & III & $\mathbf{I V}+\mathbf{V}$ \\
\hline Asthma alone $\ldots$ & $2 \cdot 5$ & $1 \cdot 4$ & $1 \cdot 4$ \\
\hline $\begin{array}{l}\text { Asthma and } \\
\text { bronchitis }\end{array}$ & $2 \cdot 7$ & $2 \cdot 3$ & $1 \cdot 5$ \\
\hline Bronchitis alone. . & $16 \cdot 5$ & $18 \cdot 6$ & $19 \cdot 7$ \\
\hline Neither & $78 \cdot 3$ & $77 \cdot 7$ & $77 \cdot 4$ \\
\hline Total percent $\quad$. & 100 & 100 & 100 \\
\hline Population & 1985 & 5745 & 2557 \\
\hline
\end{tabular}

* 684 children social class unknown

TABLE VI

PREVALENCE (\%) OF ASTHMA BY AREA OF RESIDENCE AND SOCIAL CLASS

\begin{tabular}{|c|c|c|c|c|}
\hline \multirow[b]{2}{*}{$\begin{array}{l}\text { Social } \\
\text { Class }\end{array}$} & \multicolumn{4}{|c|}{ Area of Residence } \\
\hline & $\begin{array}{l}\text { Rochester } \\
\text { (Industrial } \\
\text { Town) }\end{array}$ & $\begin{array}{l}\text { Malling } \\
\text { (Rural) }\end{array}$ & $\begin{array}{l}\text { Tonbridge } \\
\text { (Country } \\
\text { Town) }\end{array}$ & $\begin{array}{c}\text { Cranbrook } \\
\text { (Rural) }\end{array}$ \\
\hline $\mathbf{I}+\mathbf{I I} \quad \ldots$ & $6 \cdot 2$ & $5 \cdot 4$ & $5 \cdot 4$ & $3 \cdot 8$ \\
\hline III & $2 \cdot 9$ & $4 \cdot 0$ & $4 \cdot 2$ & $4 \cdot 4$ \\
\hline $\mathbf{I V}+\mathbf{V} \ldots$ & $2 \cdot 2$ & $3 \cdot 4$ & $3 \cdot 3$ & $2 \cdot 9$ \\
\hline Not known & $2 \cdot 8$ & $1 \cdot 0$ & $10 \cdot 0$ & $7 \cdot 0$ \\
\hline All ${ }^{*}$ & $3 \cdot 4$ & $3 \cdot 9$ & $4 \cdot 6$ & $3 \cdot 8$ \\
\hline Populations & 3698 & 2847 & 1875 & 2551 \\
\hline
\end{tabular}

$x^{2}=6 \cdot 10, \mathrm{df}=3, \mathrm{P}>0 \cdot 1$ 
residence did not have a significant effect on prevalence, but the social class trends noted previously were seen in each area of residence.

\section{OTHER FActors}

No difference was found in frequency of reported asthma in children from different sized families and none when they were grouped according to whether the mother worked full-time, part-time, or not at all.

School medical officers asked each child privately about his or her smoking habits. There was no difference in smoking habits between children who reported a history of asthma or bronchitis and children without such a history. However, children who had a history of both conditions were less likely to be smokers.

Analysis of the heights and weights of children with asthma and/or bronchitis in each age, sex, and social class group revealed no significant differences from the heights and weights of children who had no such history.

\section{AsSOCiATEd Illnesses}

ECZEMA AND Sinus INFECTION A highly significant association was noted between history of eczema and asthma (Table VII). Altogether 30\% of children who had asthma also had eczema as compared with only $3.7 \%$ of children who had no history of asthma. There was also a significant association between asthma and sinus infection; $8.7 \%$ of children with asthma had a history of sinus infection as compared with $4.5 \%$ without asthma. This correlation was found in both sexes but the frequency of reported eczema and sinus infection was significantly greater in boys than in girls.

BRONCHITIS The occurrence of asthma and bronchitis together in the same patient was common. As Table VIII shows, $54 \cdot 8 \%$ of boys and $59 \cdot 7 \%$ of girls who had asthma also reported having had bronchitis, compared with $20.9 \%$ and $17.8 \%$ of non-asthmatics.

TABLE VII

PROPORTION (\%) OF REPORTS OF CHILDREN WITH

\begin{tabular}{|c|c|c|c|c|c|}
\hline \multirow[b]{2}{*}{ Asthma } & \multirow[b]{2}{*}{ Total } & \multicolumn{2}{|c|}{ Eczema* } & \multicolumn{2}{|c|}{ Sinus Infection $\dagger$} \\
\hline & & Positive & Negative & Positive & Negative \\
\hline Positive & 414 & $30 \cdot 0$ & $70 \cdot 0$ & $8 \cdot 7$ & $91 \cdot 3$ \\
\hline Negative & 10554 & $3 \cdot 7$ & $96 \cdot 3$ & $4 \cdot 5$ & $95 \cdot 5$ \\
\hline
\end{tabular}

Eczema $x^{2}=610.1$, df $=1, P<0.0001$

Sinus infection $x^{2}=15.8, \mathrm{df}=1 . \mathrm{P}<0.001$

* 3 children unknown +2 children unknown
TABLE VIII

PREVALENCE (\%) OF REPORTS OF CHILDREN WITH BOTH ASTHMA AND BRONCHITIS

\begin{tabular}{|c|c|c|c|c|c|}
\hline \multirow{3}{*}{ Bronchitis } & & \multicolumn{4}{|c|}{ Asthma } \\
\hline & & \multicolumn{2}{|c|}{ Boys } & \multicolumn{2}{|c|}{ Girls } \\
\hline & & Positive & Negative & Positive & Negative \\
\hline Positive & . & $54 \cdot 8$ & $20 \cdot 9$ & $59 \cdot 7$ & $17 \cdot 8$ \\
\hline Negative & .. & $44 \cdot 8$ & $79 \cdot 0$ & $39 \cdot 6$ & $82 \cdot 2$ \\
\hline Total percent* & $\cdots$ & $99 \cdot 6$ & $99 \cdot 9$ & $99 \cdot 3$ & $100 \cdot 0$ \\
\hline Population & .. & 270 & 5259 & 144 & 5296 \\
\hline
\end{tabular}

Boys $\chi^{2}=170.8$, df $=1, P<0.001$

Girls $\chi^{2}=163 \cdot 2$, df $=1, P<0.001$

* 10 children with missing data

In view of the large proportion of asthmatics with bronchitis, or conversely bronchitics with asthma, it is possible that one disease predisposes to the other. This relationship is explored in Tables IXA and IXB for children with the onset of either disease between ages 1 and 6 , having the other disease at least 1 year and not more than 5 years later. All children who had both diseases initially diagnosed within the same year were excluded from the calculations of risk. The risk of development of asthma after bronchitis had occurred 1 or more? years previously was slightly lower than if bronchitis had not occurred. The risk of bronchitis was reduced by an earlier attack of asthma. There was no evidence that either disease predisposed to the later development of the other. Of more significance was the finding that 113 of the 177 children $(63.8 \%)$ who had both bronchitis and asthma had them within the same year. Similar results were noted for pneumonia.

TABLE IX A

NUMBERS OF CHILDREN WITH ASTHMA OR BRONCHITIS BY ORDER OF DEVELOPMENT BETWEEN AGES 1 TO 6 YEARS*

\begin{tabular}{|c|c|c|c|c|}
\hline \multirow{2}{*}{\multicolumn{2}{|c|}{ Asthma }} & \multicolumn{3}{|c|}{ Bronchitis } \\
\hline & & None & First & Second \\
\hline None & .. & 8511 & 1813 & - \\
\hline First & .. & 155 & 113 & 26 \\
\hline Second & .. & - & 38 & - \\
\hline
\end{tabular}

* 10 children with missing data excluded

52 children in whom age of onset of bronchitis/asthma not known exactly

253 children excluded if interval between bronchitis and asthma onsets was more than 5 years 
TABLE IXB

RISK OF SUBSEQUENT DEVELOPMENT OF ASTHMA OR BRONCHITIS BETWEEN AGES 1-6 YEARS*

1. Risk of asthma without any bronchitis = $155 \mid 8511+155=1 \cdot 79 \%$

2. Risk of asthma without preceding bronchitis = $(155+26) \mid 8511+155+26=2 \cdot 08 \%$

3. Risk of asthma after bronchitis = $38 \mid 1813+38=2 \cdot 05 \%$

4. Risk of bronchitis without any asthma $=$ $1813 \mid 1813+8511=17 \cdot 56 \%$

5. Risk of bronchitis without preceding asthma = $1813+38 \mid 1813+38+8511=17 \cdot 86 \%$

6. Risk of bronchitis after asthma $=$ $26 \mid 155+26=14 \cdot 36 \%$

1 v $3 \quad P>0.05 \quad 4 v 6 \quad P>0.05$

$2 v 3 \quad \mathrm{P}>0.05 \quad 5 \vee 6 \quad \mathrm{P}>0.05$

* Children with same year of onset excluded

COMPARISON OF ENVIRONMENTAL AND DEMOGRAPHIC FACTORS

The effects of different environmental and demographic variables on asthma, eczema, bronchitis, and pneumonia are summarized in Table X. Similar male preponderance in all four diseases is seen, whereas only for bronchitis does the urban (Rochester, Tonbridge) and rural (Malling, Cranbrook) gradient appear. More children with a history of asthma and eczema were found in higher social classes whereas pneumonia and bronchitis had opposite social class trends as noted previously.

\section{Peak Expiratory Flow Rate (PEFR)}

Peak expiratory flow rate varies with age, height, and weight. Therefore, for purposes of comparison this was standardized for these variables by means of appropriate multiple regression equations calculated within each age and sex group. These standardized mean PEFRs by sex and history of asthma
TABLE $X$

DIRECTION AND SIGNIFICANCE OF PARTIAL EFFECTS OF ENVIRONMENTAL ATTRIBUTES ON RESPIRATORY ILLNESSES

\begin{tabular}{|c|c|c|c|c|}
\hline Illness & Area & Social Class & Age & Sex \\
\hline Asthma $\quad \ldots$ & N S & $\quad+* * *$ & $t^{*}$ & $+* * *$ \\
\hline Eczema $\quad$. & N S & $t^{* *}$ & $-* *$ & N S \\
\hline Bronchitis .. & $+* * *$ & $-*$ & $-* * *$ & $+* * *$ \\
\hline Pneumonia & N S & $-*$ & $+* * *$ & $+*$ \\
\hline $\begin{array}{l}\text { Urban }> \\
\text { Social class I } \\
\text { Increasing pre } \\
\text { Boys }>\text { girls } \\
\text { P }<0.05\end{array}$ & $\begin{array}{l}\text { wit } \\
0.0\end{array}$ & \multicolumn{3}{|c|}{$\begin{array}{l}\text { - opposite } \\
\text { trends }\end{array}$} \\
\hline
\end{tabular}

are shown in Table XI. Within each age-sex group the mean PEFR of asthmatic children was lower than that of non-asthmatics, although these differences were statistically significant only in the older age groups. The influence of reported age of onset of asthma on the differences in mean PEFR of children at different ages was also examined, although it is not illustrated here. The numbers in each group were small, but age at onset of asthma did not seem to have a significant independent influence.

The mean PEFR of children with a history of asthma with or without bronchitis was analysed separately. The differences between mean peak flow rates of children with these various histories are shown in Table XII. There was no consistent trend in mean PEFR noted. Children who had both bronchitis and asthma did not appear to have PEFRs that were lower than those children who had only one disease.

To study the effect of asthma independent of any other factor, mean PEFRs for children with and without a history of asthma were calculated, adjusting for age, sex, height, weight, season of

TABLE XI

PEAK EXPIRATORY FLOW RATE (litres/min) BY AGE, SEX AND HISTORY OF ASTHMA (STANDARDIZED FOR AGE WITHIN EACH GROUP)

\begin{tabular}{|c|c|c|c|c|c|c|c|c|c|}
\hline \multirow{3}{*}{\multicolumn{3}{|c|}{$\begin{array}{c}\text { Asthma } \\
\text { Total Life History }\end{array}$}} & \multirow[b]{3}{*}{ Sex } & \multicolumn{6}{|c|}{ Age (Years) } \\
\hline & & & & \multicolumn{2}{|c|}{$5-8$} & \multicolumn{2}{|c|}{$9-13$} & \multicolumn{2}{|c|}{$14 t$} \\
\hline & & & & Mean & S D & Mean & S D & Mean & SD \\
\hline Positive & $\cdots$ & $\cdots$ & $\begin{array}{l}\text { Boys } \\
\text { Girls }\end{array}$ & $\begin{array}{l}129 \cdot 1 \\
125 \cdot 4\end{array}$ & $\begin{array}{l}33 \cdot 3 \\
28 \cdot 9\end{array}$ & $\begin{array}{l}279 \cdot 1 \\
251 \cdot 7\end{array}$ & $\begin{array}{l}64 \cdot 7 \\
55 \cdot 1\end{array}$ & $\begin{array}{l}344 \cdot 1 \\
305 \cdot 1\end{array}$ & $\begin{array}{l}63 \cdot 8 \\
72 \cdot 1\end{array}$ \\
\hline Negative & . & $\cdots$ & $\begin{array}{l}\text { Boys } \\
\text { Girls }\end{array}$ & $\begin{array}{l}133 \cdot 9 \\
129 \cdot 5\end{array}$ & $\begin{array}{l}33 \cdot 5 \\
32 \cdot 2\end{array}$ & $\begin{array}{l}295 \cdot 2 \\
271 \cdot 9\end{array}$ & $\begin{array}{l}48 \cdot 3 \\
53 \cdot 9\end{array}$ & $\begin{array}{l}369 \cdot 1 \\
333 \cdot 3\end{array}$ & $\begin{array}{l}60 \cdot 5 \\
68 \cdot 3\end{array}$ \\
\hline $\begin{array}{l}\text { Mean difi } \\
\text { (negative- }\end{array}$ & & . & $\begin{array}{l}\text { Boys } \\
\text { Girls }\end{array}$ & & & & & & \\
\hline
\end{tabular}


TABLE XII

PEAK EXPIRATORY FLOW RATE (litres/min) BY EXPERIENCE OF ASTHMA AND BRONCHITIS* (STANDARDIZED FOR AGE WITHIN EACH GROUP)

\begin{tabular}{|c|c|c|c|c|c|c|c|c|c|c|c|c|}
\hline \multirow{4}{*}{$\begin{array}{l}\text { Illness } \\
\text { Total Life History }\end{array}$} & \multicolumn{12}{|c|}{ Age (Years) } \\
\hline & \multicolumn{4}{|c|}{$5-8$} & \multicolumn{4}{|c|}{$9-13$} & \multicolumn{4}{|c|}{$14+$} \\
\hline & \multicolumn{2}{|c|}{ Boys } & \multicolumn{2}{|c|}{ Girls } & \multicolumn{2}{|c|}{ Boys } & \multicolumn{2}{|c|}{ Girls } & \multicolumn{2}{|c|}{ Boys } & \multicolumn{2}{|c|}{ Girls } \\
\hline & Mean & S D & Mean & S D & Mean & S D & Mean & S D & Mean & S D & Mean & S D \\
\hline Asthma and Bronchitis ... & $128 \cdot 5$ & $32 \cdot 1$ & $119 \cdot 6$ & $28 \cdot 7$ & $272 \cdot 0$ & $61 \cdot 8$ & $260 \cdot 3$ & $58 \cdot 7$ & $341 \cdot 6$ & $59 \cdot 7$ & $304 \cdot 9$ & $67 \cdot 5$ \\
\hline Asthma only $\ldots$ & $127 \cdot 1$ & $40 \cdot 3$ & $137 \cdot 4$ & $26 \cdot 2$ & $288 \cdot 3$ & $68 \cdot 2$ & $241 \cdot 2$ & $49 \cdot 3$ & $346 \cdot 9$ & $68 \cdot 5$ & $302 \cdot 5$ & $81 \cdot 8$ \\
\hline Bronchitis only & $126 \cdot 4$ & $34 \cdot 6$ & $124 \cdot 4$ & $33 \cdot 9$ & $288 \cdot 1$ & $49 \cdot 1$ & $264 \cdot 4$ & $54 \cdot 4$ & $360 \cdot 8$ & $57 \cdot 2$ & $319 \cdot 0$ & $71 \cdot 5$ \\
\hline $\begin{array}{c}\text { Neither asthma nor bron- } \\
\text { chitis }\end{array}$ & $135 \cdot 2$ & $34 \cdot 6$ & $130 \cdot 0$ & $33 \cdot 1$ & $297 \cdot 0$ & $48 \cdot 0$ & $273 \cdot 4$ & $53 \cdot 7$ & $371 \cdot 1$ & $61 \cdot 0$ & $336 \cdot 1$ & $67 \cdot 4$ \\
\hline Total & $132 \cdot 9$ & & $128 \cdot 8$ & & $294 \cdot 3$ & & $271 \cdot 2$ & & $367 \cdot 9$ & & 1192 & \\
\hline Population & 2440 & & 2275 & & 1607 & & 1706 & & 1476 & & 1457 & \\
\hline
\end{tabular}

* 10 children with missing data excluded

examination, area of residence, social class, family size, smoking habits, and reports of bronchitis, pneumonia, or whooping cough. The adjustment for all these variables was achieved by order of entry of variables into a progressive multiple regression analysis. In order to study the effect of asthma after allowing for the influence of all the other variables, asthma was the last variable entering the multiple regression equation. Table XIII shows that there was a clear difference in ventilatory function in the two older age groups even after allowance had been made for all other measured sources of variation.

The independent effects of bronchitis and pneumonia are also noted in Table XIII and adjustment was made for asthma rather than bronchitis or pneumonia. Differences were found in the level of peak flow rate between children with or without these conditions but these were smaller $(3 \%)$ than for asthma (6\%).
Discussion

We found an overall prevalence rate of $3.8 \%$ fo asthma which agrees well with data from othes studies undertaken in the United Kingdom (Dawsors et al., 1969; Smith, 1961; Graham et al., 1967) This lies midway between the Swedish prevalence figure of $0.73 \%$ (Kraepelien, 1954) and the $6.9 \%$ found in Maryland, USA (Nathanson and Rhyne 1970 ), and well below the $11 \%$ prevalence found in Melbourne, Australia (Williams and McNicol, 1969). These discrepancies may be due largely to variations in the definition of asthma and sampling procedures and to the different age structure of the study populations. A comprehensive review of the variability of asthma prevalence has recently been published (Gordis, 1973), and need not be repeated here.

One of the problems in the collection of this information is reliance for a diagnosis of asthma on the recall of symptoms and histories by the

TABLE XIII

PREDICTED PEAK EXPIRATORY FLOW RATE (litres/min) BY HISTORY OF ASTHMA, BRONCHITIS AND/OR PNEUMONIA (PEFR ADJUSTED FOR ALL OTHER VARIABLES)

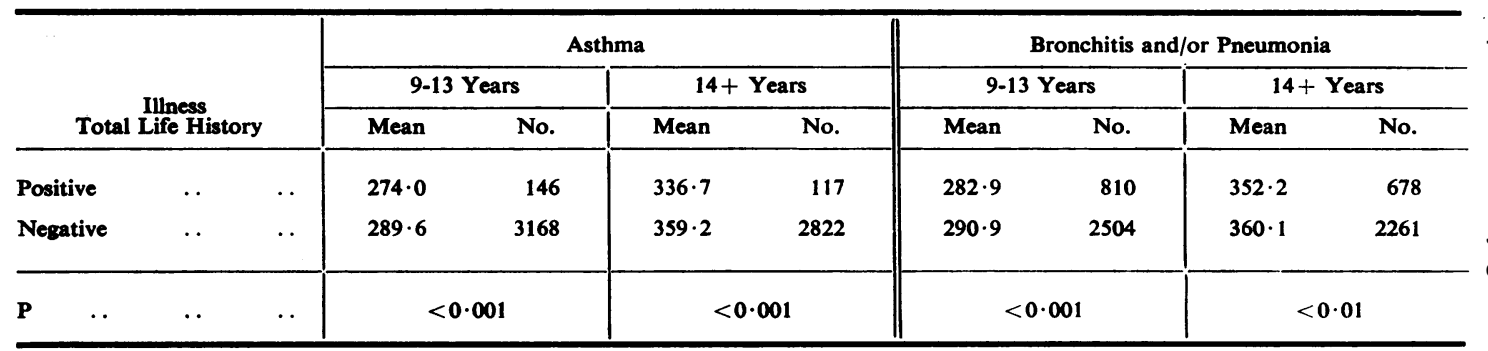


children's parents. Parents' diagnosis of specific episodes of illness may be incorrect. They may label an upper respiratory infection as bronchitis instead of asthma, or they may remember illnesses when the childien were younger more accurately than those when they were older. All data concerning the actual occurrence of disease rely on parental reporting. The records of GPs and hospitals are often incomplete because of the selective use of medical facilities. The repeat sampling 3 years after the initial survey suggested modest underreporting for asthma which would not seriously affect our results or conclusions. Previous studies have not reported follow-up validation data so strict comparison of their findings with our own is impossible.

The unsuccessful attempt to validate disease episodes from GP records emphasizes the difficulty in comparing data from different sources. The 'incompleteness' of clinical records not designed for prospective study will continue to frustrate attempts at comparison and validation.

The decreasing incidence of asthma with age, and onset in the majority of cases occurring by the age of 5 years, are findings similar to those of other studies (Dawson et al., 1969; Williams and McNicol, 1969). The numbers of children in the older age groups are too small to show significant trends in male/female differences but the male preponderance in asthma is already well documented (Dawson et al., 1969; Smith, 1961; Graham et al., 1967; Nathanson and Rhyne, 1970; Williams and McNicol, 1969). In this study it remains relatively constant with variation in area of residence, social class, and age, and in associated illness patterns, and must reflect a basic difference between the sexes rather than some socio-psychological factor as some authors have suggested (Nathanson and Rhyne, 1970). The male/female gradient in bronchitis is well recognized in adults and is usually explained by differential smoking habits and occupational exposure. But such explanations are inappropriate at ages 1 to 5 years and the finding of a similar male preponderance in young children is interesting. As the children get older this difference decreases only to reappear at a later date. Our data suggest that this is because of a relative decrease in the number of male asthmatics rather than an increase in the number of females, since after the first year of life, female incidence rates remain fairly stable until the age of 7 years.

The large number of asthmatic children with bronchitis correlates well with previous studies (Williams and McNicol, 1969; Ogilvie, 1962; Hall et al., 1972) and will be familiar to the children's physician since the similar symptoms of asthma, bronchitis, and wheezy bronchitis are often almost indistinguishable in the young. The high degree of association suggests some factor common to both conditions. Most children with both diseases in our study were reported to have had their first attack of both conditions within the same year and this finding has several possible interpretations. It could represent a memory effect-that a certain year stood out in a particular child's past and the parents related most diseases to it. It could indicate that either disease predisposes to the onset of the other within a short period of time and less so after 1 year. Or it could mean that some factor predisposes to both diseases and the clinical presentation of either is merely a different manifestation of the same process rather than an entirely separate disease.

Significantly more asthma in social classes I and II is a common finding (Graham et al., 1967; Nathanson and Rhyne, 1970), although Dawson et al. (1969) found more severe cases in the lower social class groups. A higher prevalence in the upper social classes might be due to a combination of educational and environmental factors which make such parents more aware of asthma as an entity. If this were the case, other diseases could be expected to have a similar social class distribution-bronchitis and pneumonia do not. Various social and cultural factors associated with asthmatic symptoms in children have been studied (Nathanson and Rhyne, 1970), and work on the house dust mite (Voorhurst, Spieksma-Boezeman, and Spieksma, 1964; Maunsell, Hughes, and Wraith, 1970) would suggest that it plays an important part in allergic asthma which is common in children of this age group (Williams and McNicol, 1969). The mite has a known predilection for damper environments which might have social class connotations, although seemingly in directions opposite to those found in this study. Those factors influencing mite concentrations in homes have not yet been sufficiently explored. No genetic, infectious or environmental hypothesis appears to explain these differences satisfactorily.

We found that the number of siblings in the family and mother's employment status were similar for asthmatic and non-asthmatic children. Family size and maternal presence were thus not important in this study, in contrast to other reports (Dawson et al., 1969; Nathanson and Rhyne, 1970). Bennett et al. (1971), in a previous report, found that family size, while initially appearing to be associated with lowered values for PEFR in Kent schoolchildren, was not statistically significant when all other measured factors were included in a non-orthagonal analysis of variance. 
The fact that similar proportions of asthmatic children were found in each of the four residence areas studied has three possible explanations. It could mean that environmental causes have little effect on the prevalence of asthma in children or that differing environmental factors, such as industrial air pollution and rural pollen and fungus exposure, have balanced each other. Or, thirdly, it could indicate that the differences between the four areas were not great enough. The last does not seem to be likely since the four areas in Kent did have a marked urban-rural difference and some difference in levels of air pollution (Holland et al., 1969a). Previous studies in the USA have found associations between asthma and air pollution levels in adults (Schoettlin and Landau, 1961) and hospitalization rates in children (Sultz et al., 1969). Prevalence rates of asthma in adults have been shown to be higher in rural than in urban settings both in the Netherlands (Van Der Lende, 1969) and in the United Kingdom (Holland and Reid, 1965).

It is possible that the similar proportion of asthmatics in the four areas of Kent was due to the age structure of the study population. If this had been an older group or one with a higher proportion of severe attacks, the problem of differential migration for health or occupational reasons would have to be considered. This was, however, not the case and it seems that the prevalence of asthma is related less to environmental exposure and more to still unknown endogenous factors.

The high prevalence of eczema in children with asthma has been reported elsewhere (Dawson et al., 1969; Graham et al., 1967; Williams and McNicol, 1969), and our findings confirm the excess male morbidity. If by aetiology, asthma can be classified as either extrinsic or intrinsic (Ogilvie, 1962; Ford, 1969), children with both asthma and eczema may be similar to those with an 'allergic tendency' who suffer the more extrinsic form of the disease.

Since bronchitics are not thought to have the same allergic disposition, the relation of eczema to bronchitis was examined in the same way. Altogether $30 \%$ of the children with a diagnosis of asthma had eczema, $7 \cdot 5 \%$ of the children with a diagnosis of bronchitis were also reported to have eczema. Of the 234 children reported to have both asthma and bronchitis, $30 \%$ were reported to have eczema. This suggests that the reported illnesses of asthma and bronchitis were different. That bronchitic children more often had eczema than non-asthmatic, non-bronchitic children $(4 \%)$ could be due either to misclassification of the diagnosisthat is, that these children really had asthma-or to the fact that in some bronchitic children allergic manifestations are present. Pneumonia and sinus infection were both found to be correlated with asthma. However, since both these diseases have infectious or possible allergic aetiologies, it seems likely that they are only invading hosts made more susceptible by the underlying condition of asthma.

We found that a history of asthma significantly lowers the PEFR and is independent of area, social class, or history of bronchitis or pneumonia. This appears to conflict with established thinking on asthma which considers the airway defect episodic and largely reversible (Barnett, 1972; Fraser and Paré, 1970; Wintrobe, et al., 1970). However, the finding that there is significant decrease in PEFR in asthmatic children is consistent with other clinical reports of decreased pulmonary function in the asymptomatic interval.

Weng and Levison (1969) found a reduction in maximal mid-expiratory flow (MMEF 25-75\%), during the asymptomatic interval in 30 children, and PEFR was reduced by an amount similar to thato reported here, but it was not statistically significan? because of the small numbers of patients. Leeders Woolcock, and Blackburn (1974) found an $11 \%$ reduction in PEFR in asthmatics in a study of several thousand Sydney schoolboys. Gandevia et al. (1973) also found a significant reduction i $\overrightarrow{0}$ MMEF in a study of Tasmanian schoolchildren 궁. 간 Gas exchange abnormalities have also been reporte in asymptomatic asthmatics when exercised (Levine et al., 1970).

The reduction in PEFR of asthmatic children is the same whether they have had bronchitis as well or not. The reduction of the PEFR of these children is greater than that of children who have had a history of only bronchitis.

Williams and McNicol (1969) have shown that asthmatics with age of onset at less than 2 years have significantly more frequent and prolonged subsequent attacks. Examination of PEFR for the Kent children showed that those whose stated age of onset was 2 years or before had lower mean PEFR than children whose age of onset was greater than 2 years, but only in the 5-8-year age group. This suggests that, for asthmatics in general, early age of onset by itself does not necessarily lead to significantly decreased peak flow rates. Our data did not allow examination of severity of attack, but it is probable that those more severely affected will have lower peak flow rates (Dawson et al., 1969).

There was no differential effect on levels of peak flow rate in asthmatic children living in different areas of Kent. This suggests that the area of residence factors that determine PEFR act independently of a 
history of asthma, and are more important in determining absolute levels of PEFR; the main factor appears to be air pollution (Bennett et al., 1971). The lung function of asthmatics does not seem to be more affected by these environmental factors than that of bronchitics, but small sample size did limit direct comparison.

The social and personal correlations of asthmatics identified in this study seem to be similar to those reported by others. In our sample they differ in many ways from those of children with bronchitis. Different social class trends and absence of area of residence effect on asthmatics are two of the more interesting variations. The similar patterns of onset, and the existence of a large group of asthmatics with bronchitis, suggest that possibly certain underlying factors are important in both diseases, perhaps with varying stimuli which produce differing manifestations.

It is important to ask whether the 'significant' reduction in PEFR in asthma is meaningful clinically. Certainly it raises doubts about the definition of asthma which requires reversible airways obstruction. But the definition depends, in part, on reversibility with therapy, and we know nothing about the treatment status of these children. Until longterm follow-up can be carried out on a group of asthmatics with altered flow rates, it will not be possible to forecast their prognosis conclusively.

This study has, however, shown that it is possible to detect children with impaired ventilatory function simply by asking their parents if they have had asthma in the past. We have adequate therapeutic substances to treat asthma effectively. This study certainly suggests the need for further controlled trials to determine whether the use of bronchodilators in such children prevents the development of this impairment, and whether adequate medical care of such children could alter the outcome in terms of obstructive disease of these identifiable children.

This study was supported, in part, by a generous grant from the Department of Health and Social Security. We are most grateful for all the help given by the children and parents included in the study, and the staff of Kent County Council Health and Education Departments. We should also like to thank Dr A. Elliott, Dr Chris Krupsa Wright and Dr S. Leeder. Analysis was carried out on the ULCC computer.

Requests for reprints: Professor W. W. Holland, FRCP, Department of Community Medicine, St Thomas's Hospital Medical School, London SE1 7EH.

\section{REFERENCES}

Barnett, Henry L. (ed.) (1972). Paediatrics, 15th ed. Appleton-Century-Crofts, New York.

Bennett, A. E., Holland, W. W., Halil, T., and Elliotr, A. (1971). Lung function and air pollution. Chronic inflammation of the bronchi. Progr. resp. Dis., 6, 78.

Colley, J. R. T. (1971). Respiratory disease in childhood. Brit. med. Bull., 27, 9.

Dawson, B., Horobin, G., Illsey, R., and Mitchell, R. (1969). A survey of childhood asthma in Aberdeen. Lancet, 1, 827.

Douglas, J. W. B. and Waller, R. E. (1966). Air pollution and respiratory infection in children. Brit. $J$. prev. soc. Med., $20,1$.

FERRIS, B. G. (1970). Effects of air pollution on school absences and differences in lung first and second graders in Berlin, New Hampshire, January 1966 to June 1967. Amer. Rev. resp. Dis., 102, 591.

FoRD, R. M. (1969). Aetiology of asthma: a review of 11551 cases (1958-1968). Med. J. Aust., 1, 628.

Fraser, R. G. and Paré, J. A. P. (1970). Diagnosis of Diseases of the Chest. An Integrated Study based on the Abnormal Roentgenogram. Saunders, Philadelphia.

Gandevia, B., Hall, G. J. L., Silverstone, H., and GIBsON, H. B. (1973). Respiratory disorders in sevenyear old children in Tasmania. Proceedings of the Sixth International Scientific Meeting of the International Epidemiological Association, Primosten 1971, 29 August to 3 September, Savremena Administracija, Belgrade.

GordIs, L. (1973). Epidemiology of Chronic Lung Diseases in Children, pp. 4-52. John Hopkins University Press, Baltimore.

Graham, P. J., Rutter, M. L., Yule, W., and Pless, I. B. (1967). Childhood asthma: A psychosomatic disorder? Some epidemiological considerations. Brit. J. prev. soc. Med., $21,78$.

Hall, G. J. L., Gandevia, B., Silverstone, H., Searle, J. H. A., and Gibson, H. B. (1972). The interrelationships of upper and lower respiratory tract symptoms and signs in seven-year old children. Int. J. Epid., $1,389$.

Holland, W. W., Halil, T., Bennett, A. E., and Elliotr, A. (1969a). Factors influencing the onset of chronic respiratory disease. Brit. med. J., 2, 205.

, - - , and - (1969b). Indications for measures to be taken in childhood to prevent chronic respiratory disease. Milbank mem. Fd. Quart., 47, 215.

, and -, (1970). Estimating the influence of personal and environmental factors on ventilatory function and respiratory symptoms in children. Proceedings of the 3rd International Symposium on Bronchitis, III, Groningen, The Netherlands, 23 to 26 
September 1969. edited by N. G. M. Orie and R. Van Der Lende, Royal Van Gorcum, Assen, Netherlands.

- _ - and ElliotT, A. (1969). The effect of environmental factors on ventilatory function in schoolchildren. Proceedings of 11th Aspen Emphysema Conference, Aspen, Colorado.

- and REID, D. D. (1965). The urban factor in chronic bronchitis. Lancet, 1, 445.

KraEPelien, S. (1954). The frequency of bronchial asthma in Swedish schoolchildren. Acta paediat. (Uppsala), 43, Suppl. 100, 149.

LeEDER, S. R., WOOlCOCK, A. J., and BlackbuRN, C. R. B. (1974). Assessment of ventilatory function in an epidemiological study of Sydney schoolchildren. Bull. physiopathol. Resp., 10, 635-641.

Levine, G., Housley, F., Macleod, P., and Macklem, P. T. (1970). Gas exchange abnormalities in mild bronchitis and asymptomatic asthma. New Engl. J. Med., 282, 1277.

LunN, J. E., KNowelden, J., and Handyside, A. J. (1967). Patterns of respiratory illness in Sheffield infant schoolchildren. Brit. J. prev. soc. Med., 21, 7.

Maunsell, K., Hughes, A. M., and Wraith, D. C. (1970). Mite asthma cause and management. Practitioner, 205, 779.

Nathanson, C. A. and Rhyne, M. B. (1970). Social and cultural factors associated with asthmatic symptoms in children. Soc. Sci. Med., 4, 293.

OGILvIE, A. G. (1962). Asthma. A study in prognosis of 1000 patients. Thorax, 17, 183.

REID, D. D. (1964). Air pollution and respiratory illness in children. Proceedings of the Second International Symposium on Bronchitis, II, Groningen, The Netherlands. Royal Van Gorcum, Assen, Netherlands.
Rosenbaum, S. (1961). Home localities of national servicemen with respiratory disease. Brit. J. prev. soc. Med., 15, 61.

Schoetrtin, C. E. and LANDaU, E. (1961). Air pollution and asthmatic attacks in the Los Angeles area. Publ. Hlth Rep., (Wash.), 76, 545.

SMITH, J. M. (1961). Prevalence and natural history of asthma in schoolchildren. Brit. med. J., 1, 711.

Sultz, H. A., Feldman, J. G., Schlesinger, E. R., and MOSHER, W. E. (1969). An effect of continued exposure to air pollution on the incidence of chronic childhood allergic disease. Amer. J. publ. Hlth, 60, 891.

VAN DeR Lende, R. (1969). Epidemiology of Chronic Non-Specific Lung Disease (Chronic Bronchitis) Parts I and II. The Organization for Health Research, University of Groningen, Royal Van Gorcum, Assen, Netherlands.

VoORhURST, R. SPIEKSMA-Boezeman, M. I. A., and Spieksma, F. Th. M. (1964). Is mite (dermatophagoides spp.) the producer of the house dust allergen? Allergie u Asthma, 10, 329.

Weng, Pzong-Ruey and Levison, H. (1969). Pulmonar function in children with asthma at acute attack an symptom-free status. Amer. Rev. resp. Dis., 99, 719.

Williams, H. and McNicol, K. N. (1969). Prevalence natural history and relationship of wheezy bronchiti and asthma in children. An epidemiological studx Brit. med. J., 4, 321.

Wintrobe, M. M., Thorn, G. W., Adams, R. D., BenNeTt, I. L., BRAUNWALD, E., IsSelbaChER, K. J., and Petersdorf, R. G. (Eds.) (1970). Harrison's Principles of Internal Medicine, 6th ed. McGraw-Hill, New York. 